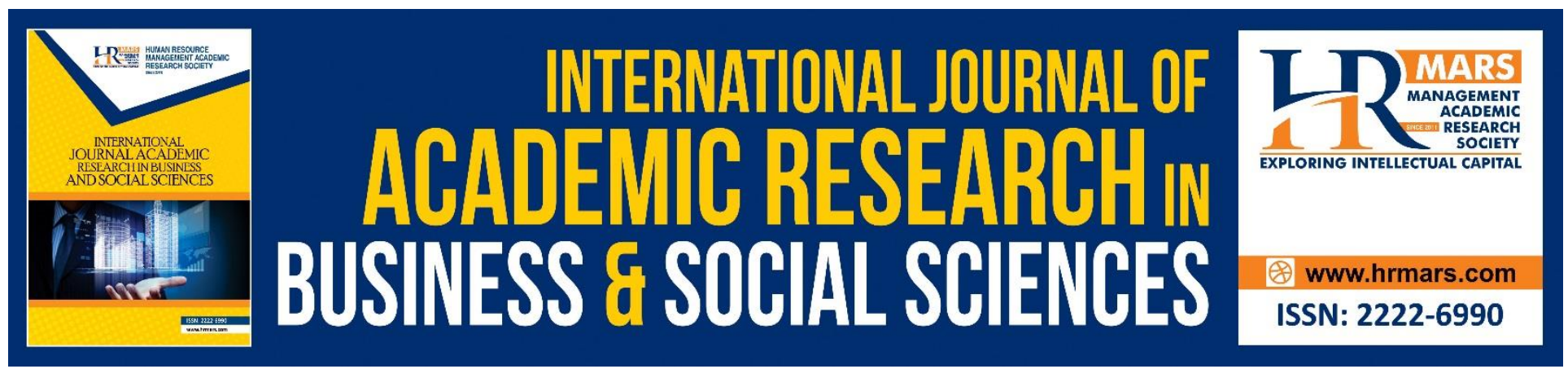

\title{
Micro Health Takaful Framework for Poor Communities in Malaysia
}

Fauzilah Salleh, Nahidah Mustafa, Wan Norhayate Wan Daud, Ahmad Shukri Yazid, Puspa Liza Ghazali, Nik Ahmad Sufian Burhan, Mohd Nazmi Hosnih

To Link this Article: http://dx.doi.org/10.6007/IJARBSS/v8-i11/5170

DOI: $10.6007 /$ IJARBSS/v8-i11/5170

Received: 03 Nov 2018, Revised: 28 Nov 2018, Accepted: 04 Dec 2018

Published Online: 05 Dec 2018

In-Text Citation: (Salleh et al., 2018)

To Cite this Article: Salleh, F., Mustafa, N., Daud, W. N. W., Yazid, A. S., Ghazali, P. L., Burhan, N. A. S., \& Hosnih, M. N. (2018). Micro Health Takaful Framework for Poor Communities in Malaysia. International Journal of Academic Research in Business and Social Sciences, 8(11), 1294-1302.

Copyright: (C) 2018 The Author(s)

Published by Human Resource Management Academic Research Society (www.hrmars.com)

This article is published under the Creative Commons Attribution (CC BY 4.0) license. Anyone may reproduce, distribute, translate and create derivative works of this article (for both commercial and non-commercial purposes), subject to full attribution to the original publication and authors. The full terms of this license may be seen at: http://creativecommons.org/licences/by/4.0/legalcode

Vol. 8, No. 11, 2018, Pg. 1294 - 1302

http://hrmars.com/index.php/pages/detail/IJARBSS

JOURNAL HOMEPAGE

Full Terms \& Conditions of access and use can be found at http://hrmars.com/index.php/pages/detail/publication-ethics 


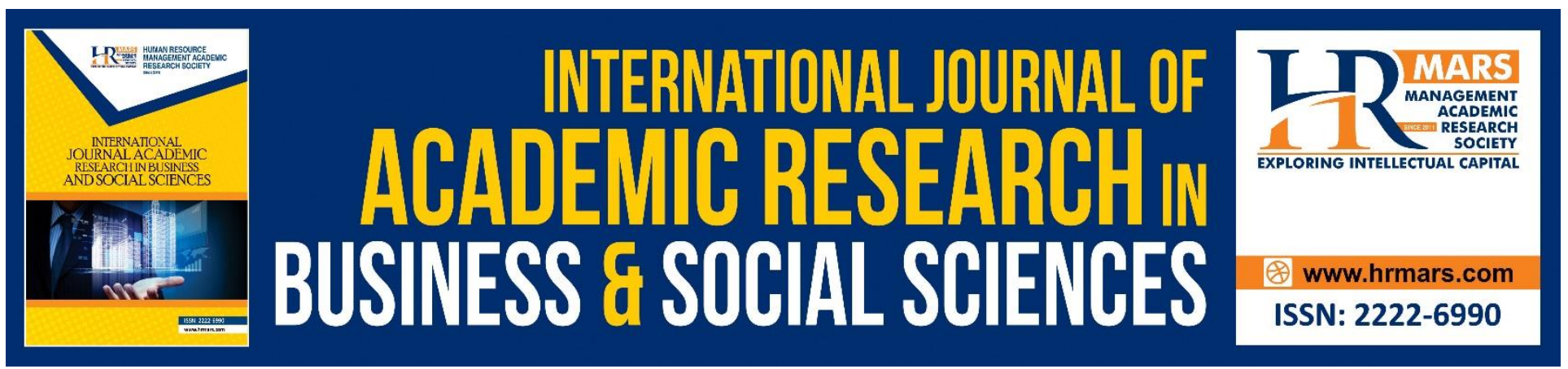

\title{
Micro Health Takaful Framework for Poor Communities in Malaysia
}

\author{
Fauzilah Salleh, Nahidah Mustafa, Wan Norhayate Wan Daud, \\ Ahmad Shukri Yazid, Puspa Liza Ghazali \\ Department of Finance, Faculty of Economics and Management Sciences, \\ Universiti Sultan Zainal Abidin, 21300 Kuala Nerus, Terengganu, Malaysia
}

\author{
Nik Ahmad Sufian Burhan \\ Department of Social and Development Sciences, Faculty of Human Ecology, \\ Universiti Putra Malaysia, Serdang, Malaysia \\ Mohd Nazmi Hosnih \\ Malaysian Takaful Association, 21st Floor, Main Block Menara Takaful Malaysia \\ No 4, Jalan Sultan Sulaiman, 50000, Kuala Lumpur, Malaysia
}

\begin{abstract}
The overall aim of this paper is to discuss health care expenses incurred and borne by the government as well as the citizens. The development of Medical and Health Insurance (MHI) / Medical and Health Takaful (MHT) in Malaysia has also been reviewed accordingly in this study. Moreover, the issues and challenges raised in regard to the implementation of Health Takaful in Malaysia has been thoroughly assessed by focusing on individuals in the low to middle level income category specifically the hard-core poor, poor and low (B40), and moderate-income earners (M40). Therefore, the aims of the paper are to present the micro health Takaful framework for the poorer communities in Malaysia.
\end{abstract}

Keywords: Micro Health Takaful, Poor Community.

\section{Introduction}

Malaysian Health Care Expenditure has been observed to have rapidly increased on the average of $12-13 \%$ per year, with the expectation that it could exceed RM20 billion by the year 2025. In 2017, the government had allocated a higher budget amounting to RM26.3 billion for providing free or almost free hospital and clinic services to the Malaysian population. However, despite the huge allocations provided for healthcare purposes, these hospitals and clinics still face difficulties to 
accommodate and fulfil the needs of the population, due to the lack of personnel as well as medicines and supplies. This leads the population especially the poor, to seek treatment from a health centre. Meanwhile, in 2016, a high number of admissions and outpatient attendances amounting to a staggering 86,237,051 patient (visits) were recorded in 141 government hospitals, whereas only a total of 5,083,596 patients were actually found in the record of 214 private hospitals. The latter, indicates that most individuals are not able to afford the services provided by private hospitals due to the high cost of treatment which is burdensome.

The National Key Results Areas (NKRAs) under the GTP have been identified to ensure the development of socio-economic growth of Malaysians. Hence, health care has been turned into one of the main priorities of this developing country based on the findings that the (standard of living) (lives) of most Malaysians are within the low to moderate level. Specifically, the low to moderate level individuals are represented in terms of hard-core poor, poor and low (B40), and moderateincome earners (M40). According to the Economic Report 2015/2016, the B40 group is categorised as those households with a monthly income of RM3,855, while the $\mathrm{M} 40$ ( $40 \%$ medium income group) are those who earn between RM3,860 and RM8,319 monthly. The Eleventh Malaysia Plan (11MP) recorded $60 \%$ of $\mathrm{B} 40$ and $\mathrm{M} 40$ are those who come from a level lower than the middle class, further showing that the government must give serious and critical attention to help improve socio-economic growth. Therefore, access to health care has become the number one priority, whereby the government has taken an action to increase the average health spending to $12-13 \%$ per year. The high budget provided by the Ministry of Health for health services, varies annually with allocations of RM19.3 billion in 2012, RM22.1 billion in 2014, and RM23.3 billion in 2015. Meanwhile, the Ministry of Health has established a program known as Malaysian Healthcare Travel Council (HTC) to further promote Malaysia as a world-class healthcare service provider.

Considering this, the government's determination is without doubt have been to developing health care services that are easily accessible with a doctor to patient ratio of 1: 6332 at 355 hospitals (141 governments \& 214 privates), 7,832 clinics with doctors (1,031 public \& 6,801 private), and 2,075 community clinics run by paramedics (Community Clinics \& 1Malaysia Clinics) (MOH, 2015). According to the report provided by the Ministry of Health (MoH) in 2015, the number of admissions to hospitals and special medical institutions were 2,465,727 60,478 and 60,478 respectively. On top of that, higher outpatients' attendances were found at hospitals with a total of 20,260,479 patients, followed by a total of 311,952 out-patients at special medical institutions, and 38,311,223 outpatients recorded at public health facilities (Ministry of Health, 2016). The percentage of total MoH allocation in the 2016 National Budget was only 8.62\% which is equivalent to RM23,031,066,400, with the breakdown for operation and development amounting to RM21,430,802,000 and RM1,600,264,400, respectively. The facilities provided at the government hospitals are limited to only 134 hospitals and nine special medical institutions, which also minimizes the services that should be made available to the public. Hence, this indicates the inadequate accessible healthcare services needed to cope with the total population that is almost approaching a total of 30 million. In 2017, the Ministry of Health recorded a total of 5,083,596 patients for both the admission and outpatient attendances at 214 private hospitals. These figures reflect that most individuals are highly dependent on government hospitals due to the affordable and almost free treatment and services provided in comparison to private hospitals. Therefore, this may be the major reason that hampers the 
INTERNATIONAL JOURNAL OF ACADEMIC RESEARCH IN BUSINESS AND SOCIAL SCIENCES Vol. 8, No. 11, Nov, 2018, E-ISSN: 2222-6990 @ 2018 HRMARS

development of health insurance in ensuring the provision of effective health care is affordable for most of the population.

One of the possible alternatives to overcome this problem is to buy health insurance; however, the existing health insurance is considered very expensive especially for the poor individuals in Malaysia. As a result, they will not even consider taking any health insurance scheme that can further prevent any future hospital costs. Therefore, it is deemed crucial to develop an affordable health Takaful framework for the poor to provide them with a prompt access to medical and health services.

\section{Literature Review}

Health care can be expensive and in the absence of insurance cover, households with severe and immediate medical needs can be forced to spend a large fraction of their household budget on health care (van Doorslaer \& O'Donnell, 2008; Burhan, Salleh \& Burhan, 2015). Hence, people in developing countries like Malaysia with three classes namely, the rich, the middle and the poor, healthcare is one of the main concerns. Poor people who are lacking access to health care will suffer a negative impact on their dignity, human capital formation and their risk-management options (Jütting, 2003). Although the health insurance schemes reaches the "poor" in general, the "chronic poor" find it financially difficult to participate. To overcome the constraints, the scheme should be well planned for targeted subsidies (partially), flexibility in payment procedure (instalment), education and strengthening of risks awareness among the poor. Hence, the establishment of mechanisms that can increase the availability and improve the quality of health care in the developing country is a matter of an urgency (Donnell, 2007). To a large extent, low- and middle-income countries health problems stems from financial deficiencies, however, spotting the limitations of a public health care system, private health insurance is a potential alternative to insure against the cost of illness (Drechsler \& Jütting, 2005). WHO records highlight that very few countries cover large parts of their health care expenses through private health insurance schemes, hence the contribution of private risk-sharing programs toward universal health coverage is thus still very limited (Drechsler \& Jütting, 2005).

In modern economies, medical or health insurance/takaful (MHI/MHT) covers the costs of medical care and majority of MHI/MHT policies usually cover general hospital and professional fees, plus a daily cash allowance for the period of the patient is warded whereby the cost of providing insurance/takaful is depending on the identity of the purchaser or insured (Abdul Rahman \& Mohd Daud, 2010). In 1999, the Central Bank of Malaysia managed to identify MHI/MHT business as an emerging trend as well as an important sector for the future of insurance and takaful industry based on the facts that ageing population seem to require higher medical costs. In this case, the number of Malaysians aged 55 and above are expected to increase due to the higher mortality rate for both males and females which are respectively recorded as 70 and 75 to 75 and 79 by the year 2020. Other than that, owing to the breakdown of the extended family structure as well as caring family values expected and advocated by the government; hence, the old-aged parents may change soon. Therefore, it is highly recommended that healthcare insurance should be turned into one of the employment benefits to ensure employees' loyalty and retention as well as for the purpose of personal income tax exemption (Abdul Rahman \& Mohd Daud, 2010). 
The above scenarios have resulted in a major change in 1999 with the establishment of the first national health insurance scheme known as SIHAT Malaysia. This scheme has attracted the participation of several local insurance companies. SIHAT Malaysia is a new hospital and surgical insurance policy that incorporates a range of hospitalization plans which are able to cater to a wide segment of society (Abdul Rahman \& Mohd Daud, 2010). Meanwhile, the Central Bank of Malaysia stated that the report on data collection and performance on MHT only started in 2003 which is the result of four Takaful operators being granted the licences to operate.

In Malaysia, there are Takaful operators and insurance companies that offer MHT/MHI. Apart from the hospitalisation and surgical insurance, dreaded diseases or critical illness insurance is also considered as one of the main concerns of modern living healthcare. Generally, there are 36 critical illnesses covered by the insurance companies and Takaful operators. Table 1 below shows the most popular medical health insurance scheme offered by Takaful operators and insurance companies in Malaysia.The medical and health Takaful schemes provide a cheaper package amounting to RM1,200 per year with a life time limit of RM650,000 based on the comparison between Takaful operators and insurance companies. On the other hand, an extremely expensive one-year premium payment provided by the insurance company is not affordable for the poor people despite the lifetime coverage provided. However, the Takaful health scheme of RM1,200 per year provided by TOA cannot be afforded by those with low income. This is evidenced by the market penetration for $\mathrm{MHI}$ and $\mathrm{MHT}$ recorded as $11.9 \%$ to $15.7 \%$ respectively of the population that possess health insurance (Naseem Aliza, 2012). Therefore, the micro medical and health scheme for the poor in Takaful Malaysia should be well developed.

Table 1: Comparison Table of the Medical Health Insurance Coverage

\begin{tabular}{|c|c|c|c|c|c|c|c|c|}
\hline \multirow{2}{*}{$\begin{array}{l}\text { Takaful } \\
\text { Operators } \\
\text { /Insurance } \\
\text { Companies }\end{array}$} & \multicolumn{2}{|c|}{$\begin{array}{l}\text { Takaful Operators } \\
\text { (TO) }\end{array}$} & \multicolumn{6}{|c|}{ Insurance Companies (IC) } \\
\hline & TOA & TOB & ICA & ICB & ICC & ICD & ICE & ICF \\
\hline $\begin{array}{l}\text { Annual } \\
\text { premium (RM) }\end{array}$ & 1,200 & 1,800 & 3,920 & 3,000 & 3,400 & 3,600 & 5,100 & 1,462 \\
\hline $\begin{array}{ll}\text { Rider or } \\
\text { Standalone }\end{array}$ & Rider & Standalone & Rider & Rider & Rider & Rider & Rider & Standalone \\
\hline $\begin{array}{l}\text { Death \& TPD } \\
\text { amount (RM) }\end{array}$ & 0 & 0 & 19,000 & $\begin{array}{l}103,00 \\
0\end{array}$ & 12,000 & 10,000 & 10,000 & 0 \\
\hline $\begin{array}{l}\text { Annual limit } \\
(A L) R M\end{array}$ & No limit & $\begin{array}{l}100,000 \\
\text { (annually } \\
\text { subject to } \\
\text { benefits } \\
\text { covered) }\end{array}$ & $\begin{array}{l}1.5 \\
\text { million }\end{array}$ & $\begin{array}{l}1.2 \\
\text { million }\end{array}$ & $\begin{array}{l}1.6 \\
\text { million }\end{array}$ & No limit & No limit & $\begin{array}{l}\text { No limit; } \\
\text { per } \\
\text { disability } \\
\text { limit of } \\
650,000\end{array}$ \\
\hline $\begin{array}{l}\text { Lifetime limit } \\
\text { (LL) RM }\end{array}$ & $\begin{array}{l}650,00 \\
0 \\
\text { (overall } \\
\text { lifetime } \\
\text { ) }\end{array}$ & No Limit & No limit & No limit & No limit & $\begin{array}{l}1.65 \\
\text { million }\end{array}$ & No limit & No limit \\
\hline
\end{tabular}

Source : Lieu, 2017; Takaful Ikhlas Berhad, 2017; AIA Public Takaful, 2017 
However, many people in the developing world go without health care from which they could benefit greatly and the poor in developing countries are even less likely than the better off to receive effective health care (Donnell, 2007). In Malaysia, healthcare is funded primarily through taxation and is no longer sustainable. Thus, a cross-sectional study was performed randomly and found that people agreed to pay for voluntary community-based health insurance (Shafie \& Hassali, 2013) showing that community-based health insurance schemes address important needs of the poor (Jütting, 2003). Due to congestion, lack of manpower, long waiting times, low access, and lack of quality and facilities at public healthcare centers, nearly $60 \%$ of Malaysians prefer to seek private primary care. However, only $18.8 \%$ of adult Malaysians are covered by voluntary private health insurance (Shafie \& Hassali, 2013). The study suggested that voluntary community-based health insurance is an attractive health financing option acceptable to Malaysians, but still needs to be reviewed for the poor and less educated community. Household income, religion, village characteristics and the belonging to a certain ethnic group exert the strongest influence on the probability of participation, thus it follows that i) although the schemes reach the "poor" in general, the "chronic poor" within the villages find it financially difficult to participate; ii) social exclusion due to factors like religion or ethnic group might prevail.

Demonstrated the importance of health insurance particularly for low and middle income, Micro Takaful that offers protection at a low contribution for the poor population as one of the major risk managing tools for the poor and low-income groups and a potential market for business. Bank Negara Malaysia (BNM) defined Micro Takaful product as a product designed to respond to the financial protection needs of low-income households. In this respect: a) Financial protection means being able to access timely and adequate financial resources that cope with major expenses and financial protection from financial burden arising from unexpected or catastrophic events, and b) Low income households refers to poor people, vulnerable or lower middle-income households, which are groups that have been previously excluded from access to insurance or takaful product.

Analysing the viability of Micro Health Takaful in Malaysia, Htay et al. (2015) revealed that Malaysian takaful operators (TOs) are keen on offering products that are affordable for middle to high income people instead of the poor and lower income people. From their findings, poor people are interested to participate in such a scheme, but mostly are only willing to contribute about RM5 per month, while some of the respondents, especially, zakat recipients are unable to afford to pay at all. Since the zakat authority responded that they were unable to contribute on behalf of the zakat recipients, where to a certain extent, an approval from the National Fatwa Council about that issue is required, the regulator views that the micro takaful is still at an experimental stage. However, from the TOs' perspective, it might be viable if the product is offered as part of their corporate social responsibility, rather than by individual operators. Therefore, it could be summarized that microhealth takaful will be viable with the agreement of TOs collectively offer it as a part of their corporate social responsibility, through subsidy by the zakat or waqf authorities.

In Malaysia, extensive research has found that most of the low income and poor people do not have adequate financial protection in mitigating their financial losses (Mohd Rom \& Abdul Rahman, 2012). Having examined the respondents within the poverty level category in the rural areas of Malaysia, Mohd Rom and Abdul Rahman (2012) discovered that $97 \%$ of them are without financial protection and unable to contribute any amount of money to get the protection. 
Researchers have suggested that the government provides the financial capacity for the poor to be principally protected for death, medical and savings benefits. The needs of the lower income can be fulfilled through micro-takaful (the concept of providing affordable protection to the poor). The government of Malaysia subsidised $58.2 \%$ of the funding in the public health sector whilst the balance of $41.8 \%$ is financed by the private sector whereby out-of-pocket payments $(73.8 \%)$ dominated by private finance sources and only a minor component covered by private insurance (13.7\%) (Yu et al., 2008). Targeting $75 \%$ of penetration rate by 2020 , promoting competitive and innovative insurance and takaful sectors remains strong, Samsudin, Abu Bakar, Regupathi and Aljunid (2016) provides further evidence from an emerging market, Malaysia, where voluntary purchase of private health insurance co-exists with almost free public health care. Also, insurance ownership was found to be significant in determining access to hospitalization be it private or public health care. This study has shown the importance and impact of having a health insurance protection which currently have yet to fully reach the target groups.

\section{Methodology}

This research utilized a multi-strategy research design by implementing both quantitative and qualitative methods. The quantitative method was conducted via survey while qualitative method was conducted via focus group discussion (FGD). Therefore, this study uses two types of analysis that differ based on the method of poor community for quantitative method and FGD conducted among Takaful operators and selected agencies to develop the framework of Takaful scheme for qualitative method. This study had used the quantitative method by employing the fieldwork technique in which questionnaires were distributed to 350 selected poor communities in 9 states in Malaysia. The study sample was chosen using the convenience sampling method to answer the questions accurately. The research instrument used in this case was the questionnaire about the amount of contribution that the respondents can afford to pay for Micro Health Takaful and on the types of illness or diseases that they are suffering.

Next, the study utilized a qualitative approach via FGD method. FGD was administered in a group of eight people in a session, accompanied by five agencies led by a moderator who followed the predesigned script and the session was in parallel with audio or video recording as evidence. According to Krueger and Casey (2000), the optimum number for the participants involvement in FGD is between six to eight participants to show a greater potential in discussing such topic, while the number of participants between six and ten are enough to achieve numerous perspective (Rabiee, 2004). Therefore, the study creates a decision to conduct FGD with eight participants as mentioned above.

Thus, the audio and video that have been recorded, generated a verbatim transcription. The whole session of FGD normally ends up between one to two hours. FGD is beneficial in producing a lively and proactive discussion and it will generate the required information. During the meeting, all collaborating agencies were exposed to the data analysed using the quantitative method which involved the data presenting the entitled diseases, medical costs incurred and value of contribution since it is the subject of the research. This was followed by a discussion on the suitability of the framework, and the flow in handling the framework of Takaful scheme. 
FGD also highlighted the issue on risk mitigation of the financial impacts or compensation correlated financial burden in medical costs. It is necessary to notify that micro health Takaful scheme is essential due to the existing economic problems and financial burden posed on the individuals. The Takaful scheme plays a significant role in lessening the burden of financial consequences and it is being used as an initial preparedness phase of an urgent situation.

The crucial parts during the discussion in FGD together with Takaful operator, Ministry of Health, Bank Negara, Zakat and academician are identifying the scheme proposed in this study, providing appropriate scheme for poor community or resident family based on the income level, deciding on compensation ratio, ensuring that comprehensive coverage is involved in the scheme, and proposing the structure of premium that should be paid by the participant. Decision on the type of coverage provided by the insurer/Takaful operator and the structure of premium specified is one of the successful strategies for risk mitigation measure (Jafee et al, 2008).

\section{Findings of the Study}

The study found that poor people are interested to participate in such a scheme, but mostly are only willing to contribute a nominal sum of about RM5-15 per month, while some of the respondents, are unwilling to pay even the RM5. Table 2 below shows the contribution affordable by the poor people.

\section{Table 2: Contribution}

\begin{tabular}{ccc}
\hline Contribution $($ RM $)$ & TOTAL RESPONDENTS & PERCENTAGE \\
\hline$<5.00$ & 92 & 26.3 \\
$5.00-10.00$ & 129 & 36.9 \\
$11.00-15.00$ & 124 & 35.4 \\
$>15.00$ & 5 & 1.4 \\
Total & 350 & 100 \\
\hline
\end{tabular}

The study also found that $32.0 \%$ of poor people suffered from diabetes, followed by fever and high blood pressure. Meanwhile other diseases are 14.6\%. Table 3 below shows the diseases suffered by the poor people in Malaysia.

Table 3: Diseases Suffered by Poor People

\begin{tabular}{ccc}
\hline Diseases & TOTAL RESPONDENTS & PERCENTAGE \\
\hline High Blood Pressure & 92 & 26.3 \\
Fever & 95 & 27.1 \\
Diabetes & 112 & 32.0 \\
Others & 51 & 14.6 \\
Total & 350 & 100 \\
\hline
\end{tabular}




\section{Conclusion}

Developing countries such as Malaysia are composed of three classes of individuals, namely the rich, middle, and poor. It is without doubt that healthcare is very important to everyone; however, the priority of each group varies accordingly. In most cases, those individuals who expect better health care service without minding the high cost of treatment tend to choose the best and most expensive insurance plan, whereas those who can only afford low-cost treatment will pick a cheaper plan. Therefore, the government of Malaysia should come out with affordable health takaful scheme for B40 group.

\section{ACKNOWLEDGMENTS}

We would also like to thank for the financial support by the Fundamental Research Grant Scheme (FRGS) from the Ministry of Education Malaysia (MOE) and Universiti Sultan Zainal Abidin, Malaysia for the technical support in completing the research.

\section{REFERENCES}

Abdul Rahman, Z., \& Mohd Daud, N. (2010). Adverse Selection and Its Consequences on Medical and Health Insurance and Takaful in Malaysia. Humanomics, 26(4), 264-283. http://doi.org/10.1108/08288661011090875.

AIA Public Takaful. (2017). A-Life Med Regular-i.

Burhan, N.A.S., Salleh, F., \& Burhan, N.M.G. (2015). National intelligence and private health expenditure: Do high IQ societies spend more on health insurance?, Intelligence, 52, 1-8.

Gupta, H. (2007). Role of Insurance Industries in Health Care Management, International Journal of Health Care \& Quality Assurance, Leeds University, U.K. Vol 21.1, October.

Htay, S. N. N., Sadzali, N. S., \& Amin, H. (2015). An Analysis of the Viability of Micro Health Takaful in Malaysia. Qualitative Research in Financial Market, 7(1), 37-71. http://doi.org/10.1108/QRFM-092013-0030.

ILO-STEP. (2005). Health micro-insurance schemes: Feasibility Study Guide (Geneva, ILOStrategies and Tools against social Exclusion and Poverty programme).

Kwon, S. (2009). Thirty years of national health insurance in South Korea: Lessons for achieving universal health care coverage. Journal of Health Policy and Planning, 63-71.

Lieu, C. F. (2017). Comparison Table of the Allianz, AIA, Great Eastern, Manulife \& Prudential Medical Insurance. Retrieved January 23, 2017, from http://www.howtofinancemoney.com/2016/03/bestmedical-card-malaysia.html.

Ministry of Health, M. (2016). Health Facts 2016.

Aliza, N. (2012) The Importance of Health Insurance Policy on Purchase Intention/Continuance - An Empirical Study in Malaysia.

Prudential BSN. (2017). PruBSN CrisisCover.

Sekhri, N. \& Savedoff, W. (2005). Policy and Practice Private health insurance : implications for developing countries. Bulletin of the World Health Organization, 010611, 127-134.

World Development Report (1993) Investing in Health, Volume 1 Published: June 1993 ISBN: 978-019-520890-0. 